\title{
Unpredictable Placental Abruption: Case Series
}

\author{
Nguyen Hong Hoa1, Nguyen Thi Mong Tuyen² \\ ${ }^{1}$ Department of Obstetrics \& Gynecology, Faculty of Medicine, University of Medicine and Pharmacy at Ho Chi Minh City, \\ Ho Chi Minh City, Vietnam \\ ${ }^{2}$ Department of Obstetrics, Tu Du Hospital, Ho Chi Minh City, Vietnam \\ Email: drhonghoa@ump.edu.vn
}

How to cite this paper: Hoa, N.H. and Tuyen, N.T.M. (2020) Unpredictable Placental Abruption: Case Series. Case Reports in Clinical Medicine, 9, 165-175. https://doi.org/10.4236/crcm.2020.96024

Received: May 24, 2020

Accepted: June 20, 2020

Published: June 23, 2020

Copyright (C) 2020 by author(s) and Scientific Research Publishing Inc. This work is licensed under the Creative Commons Attribution International License (CC BY 4.0).

http://creativecommons.org/licenses/by/4.0/ (c) (i) Open Access

\begin{abstract}
Background: The diagnosis of placental abruption is primarily clinical, but findings from imaging, laboratory, and postpartum pathologic studies can be used to support the clinical diagnosis. In patients with classic symptoms, fetal heart rate abnormalities, intrauterine fetal demise, and/or disseminated intravascular coagulation strongly support the clinical diagnosis and indicate extensive placental separation. In a few cases, placental separation has not been recognized and was only identified upon cesarean section as an incidental finding. Objectives. To describe the clinical presentations and pregnancy outcomes of placental abruption cases that are not diagnosed before cesarean delivery, termed "unpredictable placental abruption" and also cases diagnosed before cesarean delivery, termed "predictable placental abruption". Methods: A retrospective analysis of 100 cases of placental abruption was identified by cesarean delivery at $\mathrm{Tu}$ Du hospital from September 2018 to May 2019. Clinical variables were compared between the unpredictable and predictable groups. The unpredictable group consists of cases that are not diagnosed before cesarean delivery, while the predictable cases were identified placental separation before cesarean delivery. The maternal and fetal outcomes were also studied. Results. In 100 cases of placental, abruption by gross clinical examination of the placenta at the time operation revealed that, 33\% were unpredictable. Placental abruption attributed to maternal complications included one case of total hysterectomy (1\%) with no cases of disseminated intravascular coagulation (DIC), shock or maternal death; specifically, this case of total hysterectomy appeared with predictable one. There were two cases of stillbirths. Among the 98 live neonates, 15 cases (14.7\%) experienced severe birth asphyxia resulting in eight neonatal deaths; two of which were caused by heart disease and necrotizing enterocolitis. Sixty-three neonates were delivered prematurely (61.74\%), with mean gestational age of $34.64 \pm$ 3.32 weeks. Among the 33 unpredictable cases, there were no stillbirths but $60.6 \%$ and $12.1 \%$ experienced moderate and severe asphyxia, respectively. All unpredictable cases had obvious indications of cesarean section but the basic
\end{abstract}


symptoms and signs of acute placental abruption included the onset of preterm labor, unspecified intrapartum hemorrhage, hypertonic uterine contractions and fetal distress for emergency caesarian section; however there were also cases where there were no symptoms and signs. Conclusions. Unpredictable placental abruption cases-not suspected of having abruption, termed-“concealed" or "chronic" placental abruption, may have variable clinical manifestations and better pregnancy outcomes.

\section{Keywords}

Placental Abruption, Pregnancy Outcomes, Concealed Placental Abruption, Chronic Placental Abruption

\section{Introduction}

Placental abruption, defined as the complete or partial separation of the placenta before delivery, is a major cause of poor pregnancy outcome that often requires an emergency cesarean section and intensive care of the newborn. Placental abruption complicates approximately $1 \%$ of pregnancies (Ananth et al., 2015) [1] but the perinatal mortality rate is 20 -fold higher in comparison to pregnancies without abruption (12\% versus $0.6 \%$, respectively) (Tikkanen et al., 2013) [2]. For the mother, complications include hemorrhagic shock (19.4\%), Couvelaire uterus (16.5\%) and disseminated intravascular coagulation (DIC) (5.8\%) (Pitaphrom and Sukcharoen, 2006) [3]. The perinatal outcomes include low birth weight $(65.0 \%)$, preterm (56.3\%), severe birth asphyxia (16.5\%) and perinatal death (16.5\%) (Pitaphrom and Sukcharoen, 2006) [3]. A case-control study has also shown a greater risk for adverse long-term neurobehavioral outcomes for infants delivered after placental. Specifically, hypoxia-associated periventricular leukomalacia and sudden infant death syndrome are more common in newborns delivered after placental abruption (Ananth et al., 2017) [4].

While some placental abruptions may occur acutely after a sudden mechanical event (e.g., blunt trauma, sudden uterine decompression, or motor vehicle accident), more cases result from more chronic processes that are related to the abnormal development of spinal arteries and the thrombin initiating-cycle pathway of vascular disruption, hemorrhage, inflammation, as well as contractions and ruptures of membranes. The classic signs and symptoms of placental abruption are vaginal bleeding, abdominal pain, fetal distress and hypertonic uterus or tetanic contractions. The diagnosis of abruption is clinical, with ultrasonography and other tests being of limited value.

$\mathrm{Tu} \mathrm{Du}$ Hospital is the leading center in obstetrics and newborns with 2000 beds in South Vietnam. It also administrates the Minister of Health's protocols in Vietnam Women's Reproductive Health. However, in clinical practice, some cases that have poor perinatal outcomes in pregnancies are due to the discovery placental abruption after cesarean delivery. In the present study, we designed a 
retrospective, descriptive study to evaluate the clinical characteristics of cases with or without predictable placental abruptions before cesarean delivery.

\section{Methods}

The present study consisted of a retrospective review of the medical records of all patients with a diagnosis of placental abruption from September 2018 to May 2019 at Tu Du Hospital. All electronic medical records were searched for the diagnosis of placental abruption according to code O45 of the International Classification of Diseases 10 (ICD 10). Diagnoses were based on gross clinical examination of the placenta at the time of operation. The criterion for inclusion was a single pregnancy with more than 28 weeks of gestation. Cases of placenta previa and multiple gestation were excluded. Records of cases consisting of maternal and neonatal data were reviewed and collected in the data collecting form. All cased, termed "predictable" placental abruption if they were suspected before the time of operation. While, the "unpredictable" cases were not thinking of placental abruption before operation.

We collected maternal characteristics including demographic data, smoking history, past obstetric history, presenting symptoms, pertinent physical examination results, investigations performed, and complications. Neonatal data collected were gestational age at delivery, birth weight, Apgar score at 1 minute and 5 minutes, fetal death (delivery of a dead fetus at or after 28 weeks of gestation) and neonatal death.

Our research was observational study. Before going research, we were accepted by Medical Committee of University of Medicine and Pharmacy at Ho Chi Minh City, Vietnam and Tu Du Hospital. We used Stata software for describing and analyzing data.

\section{Results}

From September 2018 to May 2019, we collected 100 cases were single births with diagnoses of placental abruption. Fourteen cases were excluded due to placental previa, gestational age being less than 28 weeks, or missing data.

Demographic characteristics of placental abruption patients are shown in Table 1 . The mean maternal age of cases was $30.7 \pm 5.88$ years. Sixty percent had one or more deliveries with $27 \%$ having a history of a cesarean section. Although all cases of women reported no smoking, 27\% of their partners smoked.

Maternal and neonatal data are shown in Table 2. All study cases chosen involved cesarean sections in which the amount of blood loss was estimated to be $293.5 \pm 117.9 \mathrm{ml}$. Maternal complications only included one case of total hysterectomy with no cases of DIC, shock, and maternal death. The mean birth weight was $2274.4 \pm 117.9 \mathrm{~g}$ with $59.18 \%$ of neonates were born less than $2500 \mathrm{~g}$. There were two cases of stillbirths. Among the 98 live neonates, 15 cases (14.7\%) experienced severe birth asphyxia resulting in eight neonatal deaths; two of which were caused by heart disease and necrotizing enterocolitis. Sixty-three 
neonates were delivered prematurely $(61.74 \%)$, with mean gestational age of $34.64 \pm 3.32$ weeks. There were 58 neonates $(59.18 \%)$ that were admitted to ICU and $40(40.82 \%)$ were healthy. The length of ICU stay for neonates was approximately 9 days ( $9 \pm 6.7$ days) with a healthy recovery of 52 neonates.

Some study cases of placental abruption were identified during cesarean delivery, but there were some cases where diagnoses made before operation. Thus, we classified the former as unpredictable in 33 cases (33\%) and the latter as predictable in 67 cases $(67 \%)$ to analyze clinical presentation. Table 3 presents clinical manifestation in predictable and unpredictable placental abruption before cesarean section.

Table 1. Demographic characteristics of studying cases.

\begin{tabular}{cc}
\hline Characteristics & Cases (n=100) \\
\hline Maternal age (y) & $1(1 \%)$ \\
$<20$ & $71(71 \%)$ \\
$20-34$ & $28(28 \%)$ \\
$\geq 35$ & \\
Parity & $40(40 \%)$ \\
0 & $60(60 \%)$ \\
$1-3$ & \\
Maternal history & $27(27 \%)$ \\
Previous cesarean section & $10(10 \%)$ \\
Premature delivery & $6(6 \%)$ \\
Chronic hypertension or pregnancy induced hypertension & \\
Smoking by & $0(0 \%)$ \\
Woman & $27(27 \%)$ \\
Partner & \\
\hline
\end{tabular}

Table 2. Maternal and neonatal data.

\begin{tabular}{cc}
\hline Characteristics & Cases $(\mathrm{n}=100)$ \\
\hline Pregnancy status & \\
Gestational age at delivery (weeks) & $34.64 \pm 3.32$ \\
$28-<32$ & $21(21 \%)$ \\
$32-<34$ & $19(19 \%)$ \\
$34-<37$ & $33(33 \%)$ \\
$\geq 37$ & $37(37 \%)$ \\
Preeclampsia & $24(24 \%)$ \\
Maternal outcome & \\
Estimated blood loss (ml) & $293.5 \pm 117.9$ \\
Length of maternal hospital stay (days) & $5.1 \pm 0.7$ \\
Maternal complications & 1 (total hysterectomy) \\
Perinatal outcome & \\
Birth weight (grams) & $2274.4 \pm 764.4$ \\
Stillbirth & $2(2 \%)$ \\
Live newborn & 98 \\
Severe birth asphyxia & 15 \\
ICU & 56 \\
Neonatal death & 8 \\
LBW & 58
\end{tabular}

LBW: live born weight. 
Table 3. Clinical manifestation in predictable and unpredictable placental abruption before cesarean section.

\begin{tabular}{cccc}
\hline Characteristic & $\begin{array}{c}\text { Predictable } \\
\text { placental abruption } \\
(\mathrm{n}=67)\end{array}$ & $\begin{array}{c}\text { Unpredictable } \\
\text { placental abruption } \\
(\mathrm{n}=33)\end{array}$ & PR \\
\hline Vaginal bleeding & $35(52.24 \%)$ & $5(15.15 \%)$ & $\mathrm{P}<0.005$ \\
Abdominal pain & $14(20.90 \%)$ & $14(42.42 \%)$ & \\
Uterine tenderness, uterine tetanic & $5(7.46 \%)$ & $4(12.12 \%)$ & \\
contractions, or hypertonic uterus & & & \\
Bloody amniotic fluid & $12(17.91 \%)$ & $6(18.18 \%)$ & $\mathrm{P}>0.05$ \\
Fetal heart rate abnormalities & $13(19.40 \%)$ & $15(45.45 \%)$ & \\
Retroplacental blood & & & \\
clot by ultrasound & $54(80.60 \%)$ & $0(0.00 \%)$ & \\
Extent of abruption & & & \\
$<30 \%$ & $2(2.98 \%)$ & $22(66.67 \%)$ & \\
$30-<50 \%$ & $4(5.97 \%)$ & $8(24.24 \%)$ & \\
$50-<80 \%$ & $27(40.30 \%)$ & $2(6.06 \%)$ & \\
$80-100 \%$ & $34(50.75 \%)$ & $1(3.03 \%)$ & \\
\hline
\end{tabular}

Vaginal bleeding, which ranges from moderate to severe, related significantly to cases of predictable placental abruption before operating $(\mathrm{P}<0.005)$. More than $50 \%$ of patients in the predictable group experienced vaginal bleeding compared to only $15 \%$ of patients in the unpredictable group. However, abnormal pain, uterine tenderness, uterine tetanic contractions, or hypertonic uterus in the unpredictable group was roughly twice as high as the predictive group. Fetal heart rate abnormalities were the second most prevalent symptom in the unpredictable cases with $45.45 \%$, which is more than double that of the predictable cases. Bloody amniotic fluid was similar between the two groups with $17.91 \%$ in the predictable group and $18.18 \%$ in the unpredictable group.

The prominence of a retroplacental blood clot by ultrasound was striking. In the predictable group, $80.6 \%$ of patients had retroplacental blood clots compared to no cases in the unpredictable group.

Table 4 displays pre-operative diagnoses of 33 unpredictable placental abruptions in our study. All cases had consistent reasons for a caesarean section such as obstructed labor due to shoulder or breech presentation, and incomplete rotation of fetal head. These cases all had at least one of the basic symptoms and signs of acute placental abruption, such as vaginal bleeding, uterine contractions, and possibly a nonreassuring fetal heart rate. However, their symptoms and signs were evaluated at the onset of preterm labor, unspecified intrapartum hemorrhage, hypertonic uterine contractions, and fetal distress during emergency caesarian section. Some abruptions were asymptomatic; for instance, Case 25405, and Case 89563 with obstructed labor due to breech presentation or Case 17891 with failed medical induction of labor. Prior of operation, there were nine cases (27.3\%) of fetal stress by electrocardiograph, resulting in one severe and six moderate birth asphyxia, while there were 24 cases without fetal heart abnormal- 
ity that had three severe and fourteen moderate asphyxia. Fetal stress by electrocardiograph is not related to the worse fetal outcome or severe asphyxia in unpredictable placental abruption.

Table 5 shows the pregnancy outcome of unpredictable placental abruption cases. The mean birth weight was $2465.15 \pm 837.17$ which ranges from 1000 to $4300 \mathrm{~g}$ and $45.45 \%$ neonates were born less than $2500 \mathrm{~g}$. Among the 33 unpredictable cases, there were no stillbirths but $60.6 \%$ neonates experienced moderate asphyxia, while $12.12 \%$ experienced severe asphyxia. Six cases were less than 32 weeks of gestation with four severe and two moderate asphyxia. Thus, that there appear to be a significant correlation between premature birth and asphyxia. However, there seems to be no relationship between asphyxia and extent of placental abruption. In the unpredictable cases, there is only one case with $80 \%$ abruption, but the neonate had moderate asphyxia.

Table 4. Preoperative diagnosis (ICD-10 version) and outcomes of thirty-three cases of unpredictable placental abruption.

\begin{tabular}{|c|c|c|c|c|c|c|c|c|}
\hline & \multirow{2}{*}{ Case } & \multirow{2}{*}{ Preoperative diagnosis } & \multicolumn{3}{|c|}{ Maternal outcome } & \multicolumn{3}{|c|}{ Neonatal outcome } \\
\hline & & & Extra-c/s $\left(^{*}\right)$ & Extent of abruption & Blood lost & Age & Asphyxia $(* *)$ & Weight \\
\hline 1 & 70100 & $\begin{array}{l}\text { Labour and delivery complicated by fetal } \\
\text { stress, unspecified (068.9) }\end{array}$ & No & $20 \%$ & 500 & $36 \mathrm{w}$ & M & $2500 \mathrm{~g}$ \\
\hline 2 & 72873 & $\begin{array}{l}\text { Obstructed labour due to breech } \\
\text { presentation (064.1) }\end{array}$ & Yes (UA) & $50 \%$ & 500 & $36 \mathrm{wd}$ & M & $3000 \mathrm{~g}$ \\
\hline 3 & 74585 & Failed medical induction of labour (061.0) & No & $20 \%$ & 500 & 40w1d & No & $2900 \mathrm{~g}$ \\
\hline 4 & 74754 & $\begin{array}{l}\text { Labour and delivery complicated by other } \\
\text { evidence of fetal stress }(068.8)\end{array}$ & No & $20 \%$ & 250 & $37 \mathrm{w}$ & M & $1800 \mathrm{~g}$ \\
\hline 5 & 75265 & $\begin{array}{l}\text { Severe pre-eclampsia (014.1)—cesarean } \\
\text { scar-onset of labour }\end{array}$ & Yes (UA) & $80 \%$ & 300 & $38 \mathrm{w}$ & M & $3400 \mathrm{~g}$ \\
\hline 6 & 75399 & $\begin{array}{l}\text { Obstructed labour due to shoulder } \\
\text { presentation (064.4) — cesarean section }\end{array}$ & No & $30 \%$ & 300 & $37 w 3 d$ & M & $3000 \mathrm{~g}$ \\
\hline 7 & 83573 & $\begin{array}{l}\text { Severe pre-eclampsia }(014.1) \text {-cesarean } \\
\text { scar due to breech presentation }\end{array}$ & No & $30 \%$ & 200 & $28 w 6 d$ & M & $1000 \mathrm{~g}$ \\
\hline 8 & 87198 & $\begin{array}{l}\text { Labour and delivery complicated by other } \\
\text { evidence of fetal stress }(068.8)\end{array}$ & Yes (US) & $10 \%$ & 300 & $36 w 6 d$ & No & $3900 \mathrm{~g}$ \\
\hline 9 & 89612 & $\begin{array}{l}\text { Labour and delivery complicated by other } \\
\text { evidence of fetal stress }(068.8)\end{array}$ & Yes (UA) & $10 \%$ & 200 & $39 w$ & M & $2700 \mathrm{~g}$ \\
\hline 10 & 89910 & $\begin{array}{l}\text { Obstructed labour due to incomplete } \\
\text { rotation of fetal head }(064.0)\end{array}$ & Yes (UA) & $30 \%$ & $200 \mathrm{ml}$ & $38 \mathrm{w} 4 \mathrm{~d}$ & M & $2700 \mathrm{~g}$ \\
\hline 11 & 89563 & $\begin{array}{l}\text { Obstructed labour due to breech } \\
\text { presentation (064.1); IUGR }\end{array}$ & Yes (UA) & $15 \%$ & 200 & $36 w 6 d$ & M & $2200 \mathrm{~g}$ \\
\hline 12 & 91330 & $\begin{array}{l}\text { Labour and delivery complicated by other } \\
\text { evidence of fetal stress (068.8)_Severe } \\
\text { pre-eclampsia (014.1) }\end{array}$ & Yes (UA) & $20 \%$ & 200 & $33 \mathrm{w} 5 \mathrm{~d}$ & M & $2000 \mathrm{~g}$ \\
\hline 13 & 94317 & $\begin{array}{l}\text { Labour and delivery complicated by other } \\
\text { evidence of fetal stress (068.8) - caesarean } \\
\text { scar }\end{array}$ & Yes (UA) & $15 \%$ & 200 & $32 w 1 d$ & M & $2200 \mathrm{~g}$ \\
\hline
\end{tabular}




\section{Continued}

\begin{tabular}{|c|c|c|c|c|c|c|c|c|}
\hline 14 & 94799 & $\begin{array}{l}\text { Delivery by emergency caesarean section } \\
(082.1) \text { by uterine contractions }\end{array}$ & Yes (UA) & $10 \%$ & 200 & $39 w 1 d$ & No & $3000 \mathrm{~g}$ \\
\hline 15 & 97193 & $\begin{array}{l}\text { Delivery by elective caesarean section } \\
(082.0) \text {. PROM }\end{array}$ & No & $10 \%$ & 300 & $38 \mathrm{w}$ & $\mathrm{M}$ & $3300 \mathrm{~g}$ \\
\hline 16 & 97295 & $\begin{array}{l}\text { Obstructed labour due to shoulder } \\
\text { presentation (064.4) - PROM }\end{array}$ & No & $10 \%$ & 200 & $30 \mathrm{w}$ & S & $1350 \mathrm{~g}$ \\
\hline 17 & 100044 & $\begin{array}{l}\text { Labour and delivery complicated by other } \\
\text { evidence of fetal stress (068.8) - traffic } \\
\text { accidence }\end{array}$ & No & $20 \%$ & 200 & $35 w$ & $\mathrm{M}$ & $1900 \mathrm{~g}$ \\
\hline 18 & 104490 & $\begin{array}{l}\text { Delivery by elective caesarean section } \\
(082.0) \text { due to shoulder presentation }\end{array}$ & Yes (UA) & $15 \%$ & 200 & $30 \mathrm{w} 6 \mathrm{~d}$ & $\mathrm{M}$ & $1400 \mathrm{~g}$ \\
\hline 19 & 106584 & $\begin{array}{l}\text { Labour and delivery complicated by other } \\
\text { evidence of fetal stress }(068.8)\end{array}$ & Yes (UA) & $20 \%$ & 500 & $37 \mathrm{w} 6 \mathrm{ds}$ & No & $1900 \mathrm{~g}$ \\
\hline 20 & 916 & $\begin{array}{l}\text { Hypertonic, incoordinate, and prolonged } \\
\text { uterine contractions (062.4) — caesarean } \\
\text { section }\end{array}$ & No & $10 \%$ & 200 & $39 \mathrm{w} 3 \mathrm{ds}$ & No & $2700 \mathrm{~g}$ \\
\hline 21 & 1860 & $\begin{array}{l}\text { Pre-eclampsia superimposed on chronic } \\
\text { hypertension (011)_Caesarean section } \\
(082.0) \text { due to breech presentation }\end{array}$ & Yes (UA) & $30 \%$ & 200 & $28 \mathrm{w} 6 \mathrm{ds}$ & $S$ & $1000 \mathrm{~g}$ \\
\hline 22 & 3815 & $\begin{array}{l}\text { Labour and delivery complicated by other } \\
\text { evidence of fetal stress (068.8)-Caesarean } \\
\text { section }(082.0)\end{array}$ & Yes (UA) & $30 \%$ & 200 & $32 \mathrm{wld}$ & $\mathrm{M}$ & $1350 \mathrm{~g}$ \\
\hline 23 & 9400 & $\begin{array}{l}\text { Labour and delivery complicated by other } \\
\text { evidence of fetal stress }(068.8)\end{array}$ & No & $40 \%$ & 200 & $30 w 5 d$ & S & $1500 \mathrm{~g}$ \\
\hline 24 & 10455 & $\begin{array}{l}\text { Delivery by emergency caesarean section } \\
(082.1) \text { due to Intrapartum haemorrhage, } \\
\text { unspecified (067.9) }\end{array}$ & Yes & $10 \%$ & 800 & $37 \mathrm{w} 3 \mathrm{ds}$ & No & $2800 \mathrm{~g}$ \\
\hline 25 & 13190 & $\begin{array}{l}\text { Obstructed labour due to breech } \\
\text { presentation (064.1) }\end{array}$ & Yes (UA) & $50 \%$ & 500 & $35 \mathrm{w} 3 \mathrm{ds}$ & $\mathrm{M}$ & $2200 \mathrm{~g}$ \\
\hline 26 & 16297 & $\begin{array}{l}\text { Delivery by emergency caesarean section } \\
\text { (082.1) due to uterine contraction }\end{array}$ & No & $10 \%$ & 300 & $38 \mathrm{w} 5 \mathrm{ds}$ & No & $4300 \mathrm{~g}$ \\
\hline 27 & 17891 & Failed medical induction of labour (061.0) & No & $20 \%$ & 200 & $38 \mathrm{w} 4 \mathrm{ds}$ & sNo & $3200 \mathrm{~g}$ \\
\hline 28 & 22202 & $\begin{array}{l}\text { Obstructed labour due to breech } \\
\text { presentation (064.1) - caerarean section }\end{array}$ & $\begin{array}{l}\text { Yes } \\
\text { (B-Lynch+ } \\
\text { UA) }\end{array}$ & $20 \%$ & 600 & $35 \mathrm{w} 5 \mathrm{ds}$ & $\mathrm{M}$ & $2500 \mathrm{~g}$ \\
\hline 29 & 22465 & $\begin{array}{l}\text { Labour and delivery complicated by other } \\
\text { evidence of fetal stress (068.8)—Severe } \\
\text { pre-eclampsia (014.1)—cesarean scar }\end{array}$ & No & $10 \%$ & 300 & $31 \mathrm{w} 4 \mathrm{ds}$ & $S$ & $1450 \mathrm{~g}$ \\
\hline 30 & 22536 & $\begin{array}{l}\text { Hypertonic, incoordinate, and prolonged } \\
\text { uterine contractions }(062.4)\end{array}$ & Yes (UA) & $10 \%$ & 300 & $38 \mathrm{w} 4 \mathrm{ds}$ & $M$ & $3400 \mathrm{~g}$ \\
\hline 31 & 22617 & $\begin{array}{l}\text { Delivery by emergency caesarean section } \\
(082.1) \text { due to pain in scar }\end{array}$ & Yes (UA) & $30 \%$ & 200 & $33 \mathrm{w}$ & $\mathrm{M}$ & $2300 \mathrm{~g}$ \\
\hline 32 & 25405 & $\begin{array}{l}\text { Obstructed labour due to breech } \\
\text { presentation (064.1) - PROM }\end{array}$ & Yes (UA) & $10 \%$ & 400 & $35 \mathrm{w} 5 \mathrm{ds}$ & No & $3100 \mathrm{~g}$ \\
\hline 33 & 29322 & $\begin{array}{l}\text { Labour and delivery complicated by other } \\
\text { evidence of fetal stress (068.8) - breech } \\
\text { presentation }\end{array}$ & No & $30 \%$ & 400 & $38 w$ & $\mathrm{M}$ & $3400 \mathrm{~g}$ \\
\hline
\end{tabular}

${ }^{*}$ Extra-c/s: caesarian section with some special procedures; ${ }^{*}$ Birth asphyxia: $\mathrm{M}$ (moderate) $=$ Apgar at 1 minute $\leq 6, \mathrm{~S}($ severe) $=$ Apgar at 1 minute $\leq 4$. IUGR: Intrauterine growth restriction, PROM: Prelabor Rupture of Membranes, UA: uterine artery ligation. 
Table 5. Perinatal outcome of the unpredictable group.

\begin{tabular}{cc}
\hline Characteristics & Cases $(\mathrm{n}=33)$ \\
\hline Birth weight (grams) & $2465.15 \pm 837.17 \mathrm{~g}$ \\
Stillbirth & 0 \\
Live newborn & $33(100 \%)$ \\
Moderate birth asphyxia & $20(60.6 \%)$ \\
Severe birth asphyxia & $4(12.12 \%)$ \\
Low birth weight & $14(45.45 \%)$ \\
\hline
\end{tabular}

\section{Discussion}

The primary etiology for placental abruption is still unclear, but several possibilities have been identified, including pre-eclampsia, chronic hypertension, previous history of placental abruption, increased maternal age, cigarette smoking, and cocaine use (Tikkanen et al., 2006; Ananth, Smulian and Vintzileos, 1999) [2] [5]. In the present study, only six patients had chronic hypertension and/or pregnancy induced hypertension in the past but $24 \%$ had it during pregnancy. This finding supports other studies that have proved the strong relationship between hypertensive disorders and placental abruption. The risk for placental abruption was 4.8 -fold (95\% CI 2, 2 - 10) if both women and partners were smokers. Maternal smoking (OR 1.8; 95\% CI 1.1, 2.9) and paternal smoking (OR 2.2, 95\% CI 1.3,3.6) were found to be independently associated with placental abruption (Tikkanen et al., 2006) [6]. In our study, 27\% of partners smoked, and the case of women passive smoking should be. Our study was too small to evaluate whether passive smoking is a risk factor for placental abruption. Studied based on cotinine assessments can better evaluate the effects of passive smoking on placental abruption.

Placental abruption is associated with an increased incidence of preterm as well as maternal and perinatal morbidity. It has various presentations and severities; therefore, the maternal and perinatal outcomes are different. In our study, maternal complications involved only one case with hysterectomy, none of them expressed DIC or hemorrhagic shock that ended in death. For the mother, the potential consequence of abruption is primarily related to the severity of placental separation. The degree of abruption in our case study was mild or moderate, which was similar to the frequency of serious complications to another retrospective cohort study (33 per 10,000 women). However, serious complications were less than a study with severe abruptions (DIC: 5.8\%; hemorrhage shock: 2.9\%) (Pitaphrom and Sukcharoen, 2006) [3].

Compared to studies by Chang and Cheng (2001) [7] and Sheiner et al. [8] our study data was higher. Our incidence of preterm birth and birth asphyxia were $63 \%$ and $15.3 \%$, respectively, while $40 \%$ to $60 \%$ of abruptions occurred before 37 weeks of gestation and 14\% occurred before 32 weeks (Chang and Cheng, 2001; Sheiner et al., 2002) [7] [8]. The risks to the fetus are related to both the severity of separation and the gestation age at which delivery occurs. This explains the lower incidence of birth asphyxia in our study, while it is up to $47.6 \%$ in a study 
of severe cases (Pitaphrom and Sukcharoen, 2006) [3]. Abruption causes more severe and prolonged hypoxia than cord prolapse and is a major cause of fetal stress. Fetal asphyxia, preterm and growth restriction can contribute to poor fetal outcome. Briefly, the perinatal mortality in the present study is $8 \%$, the same as a population-based study which ranges from $3 \%$ to $12 \%$ (Ananth and VanderWeele, 2011) [9].

In our study, nearly all cases had vaginal bleeding, abdominal pain and/or uterine tenderness, hypertonic contractions, and possibly fetal heart rate abnormalities as well as presentation of acute abruption rather than chronic abruption. The unpredictable patients presented more abdominal pain, uterine contractions, and fetal heart rate abnormalities than vaginal bleeding; perhaps they had symptoms of a "concealed abruption", where all or most of the blood is trapped between the fetal membrane and decidua, rather than escaping through the cervix and vagina. Some cases may be asymptomatic and only recognized as an incidental finding during caesarean section. Almost all unsuspected placental abruption cases had one or more risk factors for pregnancy, such as preeclampsia, hypertensive disorders, malpresentation, pre-labor rupture of membranes and intrauterine growth restriction prior to caesarean section. Therefore, chronic abruption may go unsuspected because symptoms involve relatively light, intermittent bleeding and clinical manifestations of ischemic placental disease that may develop over time. Three of the unpredictable cases had intrauterine growth restriction $(106584,100044,70100)$ and were at risk of chronic abruption, but ultrasound examination could not identify a placental hematoma.

All cases, termed "predictable", were identified placental abruption by sonographic retroplacental hematoma and indicated emergency cesarean delivery. In contrast to the predictable cases, a retroplacental hematomas could not be found in the unpredictable placental abruption cases. Whether a hematoma is identified depends on the extent of hemorrhage, chronicity of the bleeding, and the amount of blood escaped through the cervix. Sonographic findings consistent with placental abruption are associated with worse maternal and perinatal outcomes. Our study may prove that unpredictable cases may be concealed or chronic abruption. In addition, almost all unpredictable cases have immediate indications of cesarean section through signs of a nonreassuring fetal heart rate, labor arrest or active labor, so that there is insufficient time to find sonographic evidence of a retroplacental hematoma. Furthermore, if an emergency cesarean delivery is required, placental abruption will be an inevitable finding.

The lack of severe pregnant outcomes in our study correlates to the degree of abruption. The extent of abruption is larger in predictable than in unpredictable cases and in most cases is smaller than 50\%. When placental separation exceeds $50 \%$, acute disseminated intravascular coagulation and fetal death are common. Therefore, unpredictable cases are not associated with worse maternal and fetal outcome. Moreover, optimal outcomes were more likely from treatment by a team of experienced obstetricians, anesthetists, and neonatologists. Cases recruited in our study were delivered by cesarean section, which is the best option 
when vaginal delivery is not imminent and rapid control of bleeding is required to prevent and manage maternal hemodynamic instability or significant coagulopathy. In the same way, cesarean section is safe choose for neonates, especially for live fetus with nonreassuring fetal status.

\section{Conclusion}

In conclusion, placental abruption with a severe degree of separation is often suspected because obvious symptoms and signs, such as vaginal bleeding, abdominal pain, fetal distress and sonographic retroplacental hematomas, which should be followed by prompt evaluation of maternal and fetal status and appropriate management. The worse pregnancy outcomes are related to severe degree of abruption. In contrast, cases not suspected of having abruption (i.e. "concealed" or "chronic" placental abruption) may have variable clinical manifestations and better pregnancy outcomes. Fetal outcomes are associated with gestational age at delivery.

\section{Limitation of the Study}

The research did not cover a long enough period of time so that strong evidence of unpredictable placental abruption was built.

\section{Conflicts of Interest}

The authors declare no conflicts of interest regarding the publication of this paper.

\section{References}

[1] Ananth, C.V., Keyes, K.M., Hamilton, A., Gissler, M., Liu, S., Luque-Fernandez, M.A., Skjærven, R., Williams, M.A., Tikkanen, M. and Cnattingius, S. (2015) An International Contrast of Rates of Placental Abruption: An Age-Period-Cohort Analysis. PloS One, 10, 0125246. https://doi.org/10.1371/journal.pone.0125246

[2] Tikkanen, M., Luukkaala, T., Gissler, M., Ritvanen, A., Ylikorkala, O., Paavonen, J., Nuutila, M., Andersson, S. and Metsäranta, M. (2013) Decreasing Perinatal Mortality in Placental Abruption. Acta Obstetricia et Gynecologica Scandinavica, 92, 298-305. https://doi.org/10.1111/aogs.12030

[3] Pitaphrom, A. and Sukcharoen, N. (2006) Pregnancy Outcomes in Placental Abruption. Journal of the Medical Association of Thailand, 89, 1572-1578.

[4] Ananth, C.V., Friedman, A.M., Lavery, J.A., VanderWeele, T.J., Keim, S. and Williams, M.A. (2017) Neurodevelopmental Outcomes in Children in Relation to pLacental Abruption. BJOG, 124, 9. https://doi.org/10.1111/1471-0528.14049

[5] Ananth, C.V., Smulian, J.C. and Vintzileos, A.M. (1999) Incidence of Placental Abruption in Relation to Cigarette Smoking and Hypertensive Disorders during Pregnancy: A Meta-Analysis of Observational Studies. Obstetrics \& Gynecology, 93, 622-628. https://doi.org/10.1016/S0029-7844(98)00408-6

[6] Tikkanen, M., Nuutila, M., Hiilesmaa, V., Paavonen, J. and Ylikorkala, O. (2006) Clinical Presentation and Risk Factors of Placental Abruption. Acta Obstetricia et Gynecologica Scandinavica, 85, 5. https://doi.org/10.1080/00016340500449915 
[7] Chang, Y.L., Chang, S.D. and Cheng. P.J. (2001) Perinatal Outcome in Patients with Placental Abruption with and without Antepartum Hemorrhage. International Journal of Gynecology \& Obstetrics, 75, 193-194. https://doi.org/10.1016/S0020-7292(01)00439-8

[8] Sheiner, E., Shoham-Vardi, I., Hadar, A., Hallak, M., Hackmon, R. and Mazor, M. (2002) Incidence, Obstetric Risk Factors and Pregnancy Outcome of Preterm Placental Abruption: A Retrospective Analysis. The Journal of Maternal-Fetal \& Neonatal Medicine, 11, 34-39. https://doi.org/10.1080/jmf.11.1.34.39

[9] Ananth, C.V. and VanderWeele, T.J. (2011) Placental Abruption and Perinatal Mortality with Preterm Delivery as a Meditor: Disentangling Direct and Indirect Effects. American Journal of Epidemiology, 174, 99-108.

https://doi.org/10.1093/aje/kwr045 